\title{
Depression and Neuropsychological Test Peformance in Acute Spinal Cord Injury Patients: Lack of Correlation
}

\author{
Gary Davidoff, * Elliot Roth, $¥$ Paula Thomas, \$ Robert Doljanac,* Marcel \\ Dijkers, $\$$ Stanley Berent, || Jeri Morris, $¥$ and Gary Yarkony† \\ Departments of *Physical Medicine and Rehabilitation and ||Psychiatry, University of \\ Michigan Medical Center, Ann Arbor, tRehabilitation Medicine Service, Veterans \\ Administration Medical Center, Ann Arbor, $\neq$ Department of Rehabilitation Medicine, \\ Northwestern University Medical Srhool, Chicago, and the $\$$ Southeastern Michigan Spinal \\ Cord Injury System, Detroit
}

Factors which have been causally related to neuropsychological deficits in acute spinal cord injury (SCI) patients include advanced age, limited educational level, acute traumatic brain injury, alcohol and/or substance abuse. Concomitant depression may impair motivation, prolong reaction time, and produce fatigue during neuropsychological testing, resulting in impaired performance. To test the hypothesis that abnormal neuropsychologic test results may be associated with depression, the Zung Self-Rating Depression Scale (ZUNG) and a comprehensive, predominantly motor-free neuropsychological test battery were administered to 66 acute SCI patients approximately 8 weeks following injury. Spinal cord injury groups were dichotomized based on their ZUNG scores. Comparison of neuropsychological test scores between SCI groups failed to demonstrate any impairment in neuropsychological performance, within the limits of the test battery administered, suggesting that cognitive performunce in this sample of acute SCI patients may not be influenced by the presence of depression.

This study was funded by a Clinical Investigator Development Award (GD) from the National Institute of Neurological and Communicative Disorders and Stroke, Bethesda, MD (NS01120), Spinal Cord Research Foundation, Paralyzed Veterans of America, Washington, D.C. (PR-529), and the Kenny Michigan Rehabilitation Foundation, Southfield, MI. Previous versions of this manuscript were thoughtfully reviewed by Bruno Giordani, PhD. Secretarial assistance was skillfully provided by Denise D. Dyson, Susan P. Moreau, and Sue Hazel.

Requests for reprints should be sent to Gary Davidoff, Rehab. Med. Svc. (117), Veterans Administration Medical Center, 2215 Fuller Road, Ann Arbor, MI 48105. 
Spinal cord injury is one of the most devastating calamities that can occur in life, with an annual incidence of $2 / 100,000$ (Kraus, Franti, Riggins, Richards, \& Borhani, 1975). Neuropsychological deficits have been observed in over $50 \%$ of acute SCI patients and have included impairments in figural and semantic recall, verbal learning, abstract reasoning, and problem-solving ability (Davidoff, Morris, Roth, \& Bleiberg, 1985b; Davidoff, Thomas, Berent, Dijkers, Klisz, Justice, Johnson, Brown, \& Cole, 1986; Davidoff, Thomas, Roth, Berent, Morris, Dijkers, Klisz, Doljanac, \& Yarkony, 1987a; Wilmot, Cope, Hall, \& Acker, 1985; Richards \& Hagglund, 1986). Various factors have been implicated in the causation of or associated with these neuropsychological deficits, including poor premorbid learning history, dyslexia, acute traumatic brain injury, and alcohol and/or substance abuse (Davidoff, Thomas, Roth, Berent, Morris, Dijkers, Klisz, Doljanac, \& Yarkony, 1987a; Wilmot, Cope, Hall, \& Acker, 1985).

The prevalence of depression in acute SCI patients has been estimated to range between 10 and 30\% (Judd, Burrows, \& Brown, 1986; Davidoff, Thomas, Roth, Berent, Morris, Dijkers, Klisz, Doljanac, \& Yarkony, 1987b; Fullerton, Harvey, Klein, \& Howell, 1981; Frank, Kashani, Wonderlich, Lising, \& Visot, 1985). Depression can potentially affect patient motivation and ability to adapt to the profound physiologic changes which occur following acute SCI, which may then compromise the patient's rehabilitation program.

Several authors have noted an association between various aspects of cognitive performance and depression. Miller and Lewis (1977) noted that elderly depressed persons had intact verbal recall, but impaired recognition memory, secondary to indecisiveness and lack of concentration. Glass, Uhlenhuth, and Weinreb (1978) noted pharmacologically reversible deficits in psychomotor performance, recognition memory and reaction time in a series of depressed outpatients.

Mungas and associates (1988) evaluated 60 psychiatric inpatients who met the Research Diagnostic Criteria for depression and found that increasing age and depression severity were associated with impaired verbal recall and information processing. Henry and associates (1973) also noted a significant negative correlation between the severity of depression and verbal recall trial performance. Sternberg and Jarvik (1976) examined 26 inpatients with depression and compared them with controls matched for age, gender, and education. Diagnosis of depression was made by clinical exam and administration of the Zung Self-Rating Depression Scale (ZUNG). Patients underwent memory testing using verbal associations, pictorial recall-recognition, and matching faces with biographical information. The depressed patients demonstrated impairment in initial and delayed verbal and figural recall. Depression and control groups had similar decrements between delayed and initial recall ([initial recall-delayed recall]/initial recall). 
Not all authors concur that depression can affect neuropsychological test performance. Gass and Russell (1986) studied 270 inpatients, with and without evidence of an organic mental syndrome and/or depression. They found no significant difference in memory test performance between depressed and nondepressed patient groups. Similar findings have been noted by Savard, Rey, and Post (1980), with respect to performance on the Halstead Category Test, and by other investigators utilizing a variety of neuropsychological assessments (Wollert \& Buchwald, 1979; Friedman, 1964).

In order to study the relationship between depression and neuropsychological performance in the SCI patient population, a group of patients with acute SCI underwent both a neuropsychological assessment and the ZUNG, and associations were examined between the results of each.

\section{METHODS}

\section{Subjects}

Sixty-six acute SCI patients who met the following criteria were invited to participate in the study protocol: age between 18 and 55 years, educational level $\geq 10$ years, and admission to one of two regional spinal cord injury care systems (Southeastern Michigan Spinal Cord Injury Care System, Detroit; or the University of Michigan Model Spinal Cord Injury System, Ann Arbor) within 45 days of onset of SCI. Patients were admitted to one of the two study sites an average of $11.8 \pm 1.8$ days (mean $\pm 1 \mathrm{SE}$ ) after injury.

\section{Procedures}

Demographic information collected on each patient included age, gender, level of education, and history of recent high-frequency alcohol or substance abuse as defined by Heineman and associates (1984). High-frequency alcohol abuse was defined as daily use of alcohol for the six-month period prior to SCI. High-frequency substance abuse was defined by daily use of marijuana, use of hallucinogens twice weekly, or cocaine and other like amphetamines thrice weekly, for the six-month period prior to SCI.

Neurologic data included level (paraplegic, quadriplegic) and etiology of SCI (e.g., road traffic accident) and presence of acute CHI coincidental to the acute SCI. Closed-head injury was defined by any interval of posttraumatic amnesia (PTA) subsequent to the injury, which could not be explained solely on the basis of anoxia or hypotension. Posttraumatic amnesia (PTA) was assessed based on the patient's ability to recollect events immediately prior to and following the accident. In those patients suspected of CHI, the duration of traumatic anterograde amnesia (PTA) was determined prospectively using the Galveston Orientation and Amnesia Test (Levin, O'Donnell, \& Grossman, 1979). The GOAT has been demonstrated 
to be a reliable instrument for the determination of PTA in SCI patients (Davidoff, Johnson, Thomas, Dijkers, Doljanac, Klisz, \& Berent, 1988). Patients who were admitted more than 24 hours after injury were evaluated by Physical Medicine and Rehabilition medical staff upon initial consultation for PTA, based on history obtained from the patient, witnesses to the accident, emergency room and acute care hospital documentation, and/or police reports. Patients with a PTA $>12$ hours were excluded from further study, in order to avoid the confounding effects of severe $\mathrm{CHI}$ on neuropsychological performance by those few patients with prolonged PTA intervals.

It was planned to exclude patients who had a past history of moderate or severe "old" closed-head injuries, as defined by Rimel and associates (1982), as well as patients with a history of a mild CHI within the six months prior to CHI (Rimel, Giordani, Barth, Boll, \& Jane, 1981). However, no patient met this exclusionary criteria. All patients with a documented history of psychosis or epilepsy were excluded from the test protocol.

Following informed consent, all patients were given the following neuropsychological test battery, an average of $65.0 \pm 3.3$ days after injury:

- The mental control subtest (MC) of the Wechsler Memory Scale (WMS) as a general test of attention (Wechsler, 1945).

- The initial and 30-minute recall of logical memory (LM-INIT, LMRECALL), associated learning (PA-INIT, PA-RECALL) and visual reproduction (VR-INIT, VR-RECALI) subtests of the WMS (Wechsler, 1945; Russell, 1975). The percent retention from the WMS was calculated by dividing the 30-minute recall score by the initial recall score, with the result multiplied by 100 (PCT-LM, PCT-PA, PCT-VR) (Russell, 1975).

- The Rey Auditory Verbal Learning Test, which gave an assessment of immediate (RAVLT I-V) and delayed recall (RAVLT VI) with interference (RAVLT B), as well as of verbal recognition memory (REY RECOG) (Lezak, 1983).

- The vocabulary subtest (VOCAB) of Wechsler Adult Intclligencc ScaleRevised (WAIS-R), as an index of premorbid intellectual functioning (Lezak, 1983).

- The Halstead Category Test, booklet form (HCT): this test was designed to assess abstract reasoning and problem solving ability as well as mental flexibility (Reitan, 1979; Kimura, 1981; DeFillipis, McCampbell, \& Rogers, 1979).

In addition, all patients completed the Zung Self-Rating Depression Scale simultaneously with the neuropsychological assessment (ZUNG) (Zung, 1965; Zung, 1971). The ZUNG is a 20-item inventory, with each item rated by the subject on a 4-point scale. The index score is calculated by summing 
all of the items and multiplying the result by 1.25 , providing a total possible score of 25 to 100 . This instrument was chosen as a screening measure because it has been demonstrated to be a valid and reliable index of presence and severity of depression (Zung, 1965; Zung, 1971; Blumenthal \& Dielman, 1975; Schaeffer, Brown, Watson, Plemel, DeMotts, Howard, Petrik, \& Balleweg 1985). Davidoff and associates (1987b) demonstrated that elevated ZUNG scores in acute SCI patients reflected elevated indices on somatic and affective items of the ZUNG, indicating that abnormally elevated ZUNG scores in this patient group were not just a reflection of the physiologic sequelae of acute SCI. Schaefer and associates (1985), compared the validities of the Beck Depression Inventory, MMPI-Depression Scale and the ZUNG in 200 psychiatric inpatients, and found that the ZUNG had the best correlation with DSM-III factor ratings for depression. Although the ZUNG cannot be considered a substitute for a comprehensive interview and clinical assessment of depression, it was felt that the ZUNG provided a reliable and objective instrument to assess depression and depressed mood (Zung, 1965; Blumenthal \& Dielman, 1975; Schaeffer, Brown, Watson, Plemel, DeMotts, Howard, Petrik, \& Balleweg, 1985). Administration of the ZUNG was delayed until an average of 65 days postinjury, in order to allow time for the patients to be transferred to the inpatient rehabilitation setting and to develop a full understanding of the physiological and psychological consequences of their traumatic SCI.

There were several unique problems associated with neuropsychological assessment of this population. Many of these patients had altered or absent hand function, secondary to quadriplegia. This precluded the use of many neuropsychological tests which require hand function or which are timed paper-and-pencil performance tasks. Second, the inability of many of these patients to sit upright for more than 60 to 90 minutes (because of increased risk of skin pressure sores) required administration of testing over several brief sessions. The total time required to administer this battery was less than three hours for the cooperative, motivated patient.

\section{Data Analysis}

Descriptive statistics were produced for age, educational level and the presence of acute closed-head injury and high-frequency alcohol or substance abuse. All confidence intervals were given as the mean \pm 1 standard error $(S E)$. In order to evaluate the relationship between demographic characteristics, neuropsychological performance and ZUNG scores, simple linear regression analysis was performed using age, education, and the ZUNG score as independent variables, and each of the neuropsychological test outcomes as dependent variables.

Patients were dichotomized into two groups on the basis of their ZUNG 
scores (ZUNG $\leq 55$, ZUNG $>55$ ). A ZUNG $>55$ was considered consistent with a clinically significant affective disorder (dysthymic disorder or major unipolar depression (Blumenthal \& Dielman, 1975). Further, all inpatients with a discharge diagnosis of depression in Zung's original work had ZUNG scores $>55$, whereas less than $10 \%$ of other psychiatric inpatients and no control subjects met or exceeded this criterion (Zung, 1965). Comparisons between neuropsychological performance between groups were performed using Student's $t$-test.

\section{RESULTS}

Eighty-two percent of the 66 acute SCI patients were male. The mean age was $29.5 \pm 1.2$ years, and the mean educational level was $12.1 \pm 0.2$ years. Twenty-nine $(41 \%)$ of the patients were quadriplegic. Most patients sustained their injuries secondary to road-traffic-related accident $(42 \%)$. Other etiologies were gunshot wounds (26\%), assaults (20\%), falls (6\%), sporting accidents $(5 \%)$, and other causes $(1 \%)$. Nine $(14 \%)$ of the sample admitted to recent high-frequency alcohol abuse, and $20(31 \%)$ to high-frequency substance abuse. Forty-one percent of the patients demonstrated evidence of an acute closed-head injury at the time of admission for emergency care for their SCI.

Thirty-three percent of all SCI patients scored in the depressed range ( $>$ 55) on the ZUNG scale (Blumenthal \& Dielman, 1975). No significant differences were noted in the mean ages or years of education between patient groups, dichotomized by ZUNG scores (Table 1). There were also no significant differences between SCI groups with respect to gender, geographic location (Detroit or Ann Arbor), presence of acute closed-head injury, or history of recent alcohol or substance abuse (Table 1).

TABLE 1

Comparability of Demographic Characteristics Among Spinal Cord Injury Groups

\begin{tabular}{lccc}
\hline & ZUNG $>55$ & \multicolumn{2}{c}{ ZUNG $\leq 55$} \\
& $N=21$ & $N=45$ & Statistic \\
\hline Age (years) & $29.0 \pm 2.1$ & $29.8 \pm 1.5$ & $t(64=0.30$ \\
Education (years) & $12.3 \pm 0.5$ & $11.9 \pm 0.3$ & $t(63)=-0.72$ \\
Gender (male) & $86 \%$ & $80 \%$ & $*$ \\
Location (Detroit) & $52 \%$ & $71 \%$ & $(1)=0.60$ \\
Closed head injury & $33 \%$ & $44 \%$ & $(1)=0.73$ \\
Alcohol abuse & $10 \%$ & $16 \%$ & $*$ \\
Substance abuse & $33 \%$ & $30 \%$ & $(1)=0.9$ \\
\hline
\end{tabular}

All values given as mean $\pm 1 \mathrm{SE}$.

No statistic was significant at the 0.05 level.

*Denotes Fisher's exact test. 
TABLE 2

Squared Correlation Coefficients $\left(r^{2}\right)$ Between Neuropsychological Test Scores and A Education and ZUNG Scores

\begin{tabular}{lccc}
\hline Test & $\begin{array}{c}\text { Age } \\
\text { (years) }\end{array}$ & $\begin{array}{c}\text { Education } \\
\text { (years) }\end{array}$ & ZUNG \\
\hline Mental Control & $\mathrm{ns}$ & $\mathrm{ns}$ & $\mathrm{ns}$ \\
Logical Memory (initial recall) & $\mathrm{ns}$ & $\mathrm{ns}$ & $\mathrm{ns}$ \\
Logical Memory (delayed recall) & $0.06^{*}$ & $\mathrm{~ns}$ & $\mathrm{~ns}$ \\
Logical Memory (percent retention) & $\mathrm{ns}$ & $\mathrm{ns}$ & $\mathrm{ns}$ \\
Paired Associates (initial recall) & $\mathrm{ns}$ & $\mathrm{ns}$ & $\mathrm{ns}$ \\
Paired Associates (delayed recall) & $\mathrm{ns}$ & $\mathrm{ns}$ & $0.08^{*}$ \\
Paired Associates (percent retention) & $\mathrm{ns}$ & $\mathrm{ns}$ & $\mathrm{ns}$ \\
Visual Reproduction (initial recall) & $0.11^{* *}$ & $0.08^{*}$ & $\mathrm{~ns}$ \\
Visual Reproduction (delayed recall) & $\mathrm{ns}$ & $\mathrm{ns}$ & $0.10^{*}$ \\
Visual Reproduction (percent recall) & $\mathrm{ns}$ & $\mathrm{ns}$ & $\mathrm{ns}$ \\
Vocabulary Subtest (WAIS-R) & $\mathrm{ns}$ & $0.42^{* * *}$ & $\mathrm{~ns}$ \\
Rey Auditory Verbal Learning Test, Trial I & $\mathrm{ns}$ & $0.07^{*}$ & $\mathrm{~ns}$ \\
Rey Auditory Verbal Learning Test, Trial II & $0.11^{*}$ & $\mathrm{~ns}$ & $\mathrm{~ns}$ \\
Rey Auditory Verbal Learning Test, Trial III & $0.21^{* * *}$ & $\mathrm{~ns}$ & $\mathrm{~ns}$ \\
Rey Auditory Verbal Learning Test, Trial IV & $0.15^{* * *}$ & $0.12^{* *}$ & $\mathrm{~ns}$ \\
Rey Auditory Verbal Learning Test, Trial V & $0.24^{* * *}$ & $0.11^{* *}$ & $\mathrm{~ns}$ \\
Rey Auditory Verbal Learning Test, Trial B & $0.11^{* *}$ & $\mathrm{~ns}$ & $\mathrm{~ns}$ \\
Rey Auditory Verbal Learning Test, Trial VI & $0.18^{* * *}$ & $\mathrm{~ns}$ & $\mathrm{~ns}$ \\
Rey Auditory Verbal Learning Test, Recognition Trial & $\mathrm{ns}$ & $\mathrm{ns}$ & $\mathrm{ns}$ \\
Halstead Category Test, Total Errors & $\mathrm{ns}$ & $\mathrm{ns}$ & $\mathrm{ns}$ \\
\hline
\end{tabular}

$\mathrm{ns}=$ not significant; ${ }^{*} p<0.05 ;{ }^{* *} p<0.01 ; * * * p<0.0005$.

Linear regression analyses revealed modest but significant correlations between age and most trials of the Rey Auditory Verbal Learning Test (RAVLT), VR-INIT and LM-RECALL (Table 2). Number of years of education was significantly correlated with most trials of the R-AVLT, VR-INIT, and the PCT-PA. ZUNG scorcs wcre corrclated with PA-RECALL and VRRECALL, with $10 \%$ or less of the variance accounted for by the ZUNG index score.

Means and $1 S E$ confidence intervals for results of each neuropsychological test were calculated for each SCI group dichotomized by ZUNG score (Table 3). There were no significant differences in neuropsychological test scores between groups (Table 3).

\section{DISCUSSION}

It is estimated that $50-60 \%$ of all acute SCI patients have mild to severe deficits in the areas of abstract reasoning, problem-solving ability, and immediate and delayed recall of verbal or nonverbal material (Davidoff, Morris, Roth, \& Bleiberg, 1985b; Davidoff, Thomas, Berent, Dijkers, Klisz, Justice, Johnson, Brown, \& Cole, 1986; Davidoff, Thomas, Roth, Berent, 
TABLE 3

Comparison of Neuropsychological Test Measures among SCI Patients Dichotomized by ZUNG Scores

\begin{tabular}{lrrrr}
\hline Test & ZUNG $>55$ & ZUNG $\leq 55$ & $d f$ & $t$-stat \\
\hline Mental Control & $6.6 \pm 0.5$ & $7.0 \pm 0.3$ & 64 & 0.77 \\
Logical Memory (initial recall) & $8.7 \pm 0.8$ & $10.2 \pm 0.5$ & 63 & 1.67 \\
Logical Memory (delayed recall) & $7.2 \pm 0.7$ & $8.2 \pm 0.5$ & 63 & 1.08 \\
Logical Memory (percent retention) & $86.6 \pm 6.2$ & $78.8 \pm 3.3$ & 63 & -1.22 \\
Paired Associates (initial recall) & $9.2 \pm 0.5$ & $10.3 \pm 0.3$ & 63 & 1.84 \\
Paired Associates (delayed recall) & $4.9 \pm 0.3$ & $5.3 \pm 0.2$ & 60 & 1.29 \\
Paired Associates (percent retention) & $53.7 \pm 2.6$ & $52.9 \pm 1.7$ & 60 & -0.27 \\
Visual Reproduction (initial recall) & $9.7 \pm 0.8$ & $10.5 \pm 0.5$ & 46 & 0.98 \\
Visual Reproduction (delayed recall) & $7.8 \pm 1.0$ & $9.4 \pm 0.6$ & 43 & 1.29 \\
Visual Reproduction (percent recall) & $80.0 \pm 8.5$ & $85.9 \pm 4.2$ & 43 & 0.68 \\
Vocabulary Subtest (WAIS-R) & $36.5 \pm 3.2$ & $37.4 \pm 2.0$ & 63 & 0.27 \\
Rey Auditory Verbal Learning Test, Trial I & $6.9 \pm 0.6$ & $6.7 \pm 0.3$ & 62 & -0.42 \\
Rey Auditory Verbal Learning Test, Trial II & $9.5 \pm 0.6$ & $9.1 \pm 0.3$ & 61 & -0.58 \\
Rey Auditory Verbal Learning Test, Trial III & $10.1 \pm 0.6$ & $10.7 \pm 0.3$ & 62 & 0.98 \\
Rey Auditory Verbal Learning Test, Trial IV & $11.8 \pm 0.2$ & $11.7 \pm 0.3$ & 62 & 0.14 \\
Rey Auditory Verbal Learning Test, Trial V & $12.6 \pm 0.6$ & $12.1 \pm 0.3$ & 62 & -0.81 \\
Rey Auditory Verbal Learning Test, Trial B & $0.6 \pm 0.3$ & $5.4 \pm 0.3$ & 61 & -1.24 \\
Rey Auditory Verbal Learning Test, Trial VI & $10.6 \pm 0.4$ & $10.6 \pm 0.5$ & 60 & 0.08 \\
Rey Auditory Verbal Learning Test, Recognition & & & & \\
$\quad$ Trial & $13.5 \pm 0.5$ & $13.4 \pm 0.2$ & 61 & -0.25 \\
Halstead Category Test, Total Errors & $63.0 \pm 6.8$ & $56.4 \pm 4.5$ & 61 & -0.82 \\
\hline
\end{tabular}

All values given as the mean $\pm S E$.

No comparison achieved statistical significance.

Morris, Dijkers, Klisz, Doljanac, \& Yarkony, 1987a; Wilmot, Cope, Hall, \& Acker, 1985; Richards \& Hagglund, 1986). Factors which may contribute to neurocognitive dysfunction in this patient group include poor premorbid learning history, acute traumatic brain injury associated with the acute SCI, and/or a history of recent high-frequency alcohol or substance abuse (Davidoff, Thomas, Roth, Berent, Morris, Dijkers, Klisz, Doljanac, \& Yarkony, 1987a; Wilmot, Cope, Hall, \& Acker, 1985). Another factor which may be implicated as contributing to impaired neuropsychological test performance in acute SCI patients is depression. Estimates of the prevalence of major depression (by DSM-III criteria) in acute SCI patients vary between $10 \%$ and 30\% (Judd, Burrows, \& Brown, 1986; Davidoff, Thomas, Roth, Berent, Morris, Dijkers, Klisz, Doljanac, \& Yarkony, 1987b; Fullerton, Harvey, Klein, \& Howell, 1981; Frank, Kashani, Wonderlich, Lising, \& Visot, 1985).

In the present study, $33 \%$ of the SCI patients had abnormally elevated ZUNG scores. Spinal cord injury patient groups dichotomized by ZUNG scores had similar ages and levels of education, and similar frequency distributions of potentially confounding variables. Linear regression analysis indicated statistically significant relationships between age and semantic (ver- 
bal) short-term and long-term recall and VR-RECALL (Table 2). These findings have been noted by other investigators in various patient populations and in normal controls (Prigatano \& Parsons, 1976; Finlayson, Johnson, \& Reitan, 1977; desRosiers \& Ivison, 1986). In this study, years of education had modest but statistically significant correlations with initial and delayed semantic recall and PCT-PA. There was also a robust relationship between educational level and the VOCAB subtest of the WAIS-R $\left(r^{2}=0.42\right)$. The relationship between VOCAB and education was as expected, since the VOCAB subtest was used as an indirect measure of premorbid level of intellectual functioning (Lezak, 1983).

The only correlations noted between the ZUNG and neuropsychological test scores were for VR-RECALL and PA-RECALL. Likewise, Stromgren (1977) demonstrated statistically significant but weak correlations between elements of the Wechsler Memory Scale (WMS), but the overall variance in WMS performance explained for by depression scores generally was less than 10\%. However, based on the findings of other investigators (Mungas, Blunden, \& Ehlers, 1988; Henry, Weingarten, \& Murphy, 1973), one might have expected a substantial correlation between the ZUNG and all serial word trials of the REY AVLT (AVLT TRIALS I-VI). Additionally, it might have been expected that more generalized impairment would have been found in initial and delayed recall for the WMS subtests than was actually noted.

Comparisons of the means for each of the neuropsychological test measures between SCI patients, dichotomized by ZUNG scores, indicated no significant difference in performance between groups. These findings differ from those of other investigators (Mungas, Blunden, \& Ehlers, 1988; Henry, Weingarten, \& Murphy, 1973; Sternberg \& Jarvis, 1976) in part, perhaps because these authors failed to restrict subject selection to adequately control for potential confounders (e.g., level of education). The selection of subjects in this study was carefully restricted to limit the confounding effects of level of education, severity of acute closed-head injury, and other variables. It could be argued that neuropsychological performance might be impaired between different patient groups, based on differing levels of ZUNG scores (e.g., normal, mild, moderate, severe). However, the regression analysis failed to show any consistent relationship between neuropsychological performance and the ZUNG. The former method would have transformed a continuous measure (the ZUNG) into an ordinal measure, which would have led to statistical analyses with less power.

The findings of this study are comparable to those of other investigators (Gass \& Russell, 1986; Friedman, 1964; Savard, Rey, \& Post, 1980) who found little difference in cognitive performance between depressed and nondepressed subjects in various patient cohorts. Although there is substantial documentation of psychomotor retardation in depressed patients (Wollert \& 
Buchwald, 1979; Weckowicz, 1972; Weckowicz, Tam, Mason, \& Bay, 1978), measures of psychomotor function were not evaluated in this study due to the impaired hand function and motor control in many of the SCI patients studied.

Depression is a rather prevalent condition in patients who have sustained an acute SCI (Judd, Burrows, \& Brown, 1986; Davidoff, Thomas, Roth, Berent, Morris, Dijkers, Klisz, Doljanac, \& Yarkony, 1987b; Fullerton, Harvey, Klein, \& Howell, 1981; Frank, Kashani, Wonderlich, Lising, \& Visot, 1985). Although many factors may play a role in the impaired neurocognitive functioning found in this patient group, it would seem that depression, as measured indirectly by ZUNG scores in this study, had little, if any effect on neuropsychological test performance or impairment in the battery utilized in this investigation. It is possible that other neuropsychological assessments, particularly of psychomotor ability and reaction time, might demonstrate such effects. These results suggest that depression (or depressed affect) and impaired cognitive performance in the acute SCI patient are two separate problems which are casually but not causally related.

\section{REFERENCES}

Blumenthal, M. D., \& Dielman, T. E. (1975). Depression symptomatology and role function in a general population. Archives of General Psychiatry, 32, 985-991.

Davidoff, G., Johnson, M. B., Thomas, P., Dijkers, M., Doljanac, R., Klisz, D., \& Berent, S. (1988). Utility of the Galveston Orientation and Amnesia Test in the determination of closed head injury in acute spinal cord injury patients. Archives of Physical Medicine and Rehabilitation, 69, 432-434.

Davidoff, G., Morris, J., Roth, E., \& Bleiberg, J. (1985a). Closed head injury in spinal cord injured patients: Retrospective study of loss of consciousness and post-traumatic amnesia. Archives of Physical Medicine and Rehabilitation, 66, 41-43.

Davidoff, G., Morris, J., Roth, E., \& Bleiberg, J. (1985b). Cognitive dysfunction and mild closed head injury in traumatic spinal cord injury. Archives of Physical Medicine and Rehabilitation, 66, 489-491.

Davidoff, G., Thomas, P., Berent, S., Dijkers, M., Klisz, D., Justice, P., Johnson, M., Brown, M., \& Cole T. (1986). Cognitive performance in acute spinal cord injury patients. Archives of Physical Medicine and Rehabilitation, 67, 653.

Davidoff, G., Thomas, P., Roth, E., Berent, S., Morris, J., Dijkers, M., Klisz, D., Doljanac, R., \& Yarkony, G. (1987a). Three center study of risk factors for cognitive impairment in acute spinal cord injury patients. Archives of Physical Medicine and Rehabilitation, 68, 673-674.

Davidoff, G., Thomas, P., Roth, E., Berent, S., Morris, J., Dijkers, M., Klisz, D., Doljanac, R., \& Yarkony, G. (1987b). Risk factors for depression among acute spinal cord injury patients. Archives of Physical Medicine and Rehabilitation, 68, 673.

DeFillipis, N. A., McCampbell, E., \& Rogers, P. (1979). Development of a booklet form of the category test. Normative and validity data. Journal of Clinical Neuropsychology, 1, 339342.

desRosiers, G., \& Ivison, D. (1986). Paired associate learning: Normative data for differences between high and low associate word pairs. Journal of Clinical and Experimental Neuropsychology, 8, 637-642. 
Finlayson, M. A. J., Johnson, K. A., \& Reitan, R. M. (1977). Relationship of level of education to neuropsychological measures in brain-damaged and non-brain-damaged adults. Journal of Consulting and Clinical Psychology, 45, 536-542.

Frank, R. G., Kashani, J. H., Wonderlich, S. A., Lising, A., \& Visot, L. R. (1985). Depression and adrenal function in spinal cord injury. American Journal of Psychiatry, 142, 243252.

Friedman, A. S. (1964). Minimal effects of severe depression on cognitive functioning. Journal of Abnormal and Social Psychology, 69, 237-243.

Fullerton, D. T., Harvey, R. F., Klein, M. H., \& Howell, T. (1981). Psychiatric disorders in patients with spinal cord injuries. Archives of General Psychiatry, 38, 1369-1371.

Gass, C. S., \& Russell, E. W. (1986). Differential impact of brain damage and depression on memory test performance. Journal of Consulting and Clinical Psychology, 54, 261-263.

Glass, R. M., Uhlenhuth, E. H., \& Weinreb H. (1978). Imipramine-reversible cognitive deficit in outpatient depressives. Psychopharmacology Bulletin, 14, 10-13.

Heineman, A., Donohue, R., \& Adair, W. (1984). Characteristics of high frequency, substance using inpatients: Preliminary data. Archives of Physical Medicine and Rehabilitation, 65, 623.

Henry, G. M., Weingartner, H., \& Murphy, D. L. (1973). Influence of affective states and psychoactive drugs on verbal learning and memory. American Journal of Psychiatry, 130, 966-971.

Judd, F. K., Burrows, G. D., \& Brown, D. J. (1986). Depression following acute spinal cord injury. Paraplegia, 24, 358-363.

Kimura, S. (1981). Card form of the Reitan-modified Halstead Category Test. Journal of Consulting and Clinical Psychology, 49, 145-146.

Kraus, J. F., Franti, C. E., Riggins, R. S., Richards, D., \& Borhani, N. O. (1975). Incidence of traumatic spinal cord lesions. Journal of Chronic Disease, 28, 471-492.

Levin, H. S., O'Donnell, V. W., \& Grossman, R. G. (1979). The Galveston orientation and amnesia test. A practical scale to assess cognition after head injury. Journal of Nervous and Mental Disorders, 167, 675-684.

Lezak, M. D. (1983). Neuropsychological assessment. Oxford: Oxford University Press.

Miller, E., \& Lewis, P. (1977). Recognition memory in elderly patients with depression and dementia: A signal detection analysis. Journal of Abnormal Psychology, 86, 84-86.

Mungas, D., Blunden, D., \& Ehlers, C. (1988). Depression and age effects in verbal learning. Journal of Clinical and Experimental Neuropsychology, 10, 81-82.

Prigatano, G. P., \& Parsons, O. A. (1976). Kelationship of age and education to Halstead test performance in different patient populations. Journal of Consulting and Clinical Psychology, 44, 527-533.

Reitan, R. M. (1979). Manual for administration of neuropsychological test batteries for adults and children. Privately published by the author. Tucson.

Richards, J. S., \& Hagglund, K. (1986). Spinal cord injury and closed head injury: Coincidence rates based on a longitudinal investigation. Archives of Physical Medicine and Rehabilitation, 67, 658.

Rimel, R. W., Giordani, B., Barth, J. T., \& Jane, J. A. (1982). Moderate head injury: Completing the clinical spectrum of brain trauma. Neurosurgery, 11, 344-351.

Rimel, R. W., Giordani, B., Barth, J. T., Boll, T. J., \& Jane, J. A. (1981). Disability caused by minor head injury. Neurosurgery, 9, 221-228.

Russell, E. W. (1975). A multiple scoring method of the assessment of complex memory functions. Journal of Consulting and Clinical Psychology, 43, 800-809.

Savard, R. J., Rey, A. C., \& Post, R. M. (1980). Halstead-Reitan Category Test in bipolar and unipolar affective disorders: Relationship to age and phase of illness. Journal of Nervous and Mental Disorders, 168, 297-304.

Schaeffer, A., Brown, J., Watson, C. G., Plemel, D., DeMotts, J., Howard, M. T., Petrik, N., 
\& Balleweg, B. J. (1985). Comparison of the validities of the Beck, Zung, and MMPI Depression Scales. Journal of Consulting and Clinical Psychology, 53, 415-418.

Sternberg, D. E., \& Jarvik, M. E. (1976). Memory functions in depression: Improvement with antidepressant medication. Archives of General Psychiatry, 33, 219-224.

Stromgren, L. S. (1977). The influence of depression on memory. Acta Psychiatry Scandinavia, 56, 109-128.

Wechsler, D. (1945). A standardized memory scale for clinical use. Journal of Psychology, 19, 87-95.

Weckowicz, T. E., Nutter, R. W., Cruise, D. G. \& Yonge, K. A. (1972). Speed in test performance in relation to depressive illness and age. Canadian Psychiatry Association Journal, 17, 241-250.

Weckowicz, T. E., Tam, C. H. I., Mason, J., \& Bay, E. S. (1978). Speed in test performance in depressed patients. Journal of Abnormal Psychology, 87, 578-582.

Wilmot, C. B., Cope, D. N., Hall, K. M. \& Acker, M. (1985). Occult head injury: Its incidence in spinal cord injury. Archives of Physical Medicine and Rehabilitation, 66, 227-231.

Wollert, R. W., \& Buchwald, A. M. (1979). Subclinical depression and performance expectations, evaluations of performance, and actual performance. Journal of Nervous and Mental Disorders, 167, 237-242.

Zung, W. W. K. (1965). A Self-Rating Depression Scale. Archives of General Psychiatry, 12, 63-70.

Zung, W. W. K. (1971). Depression in the normal adult population. Psychosomatics, 12, 164167. 